\title{
The Analysis and Assessment of Adjustment of Selected Web Sites and Web Browsers to the Needs of People with Disabilities
}

\author{
Aleksandra Polak-Sopińska and Zbigniew Wiśniewski \\ Institute of Production Management, Technical University of Lodz, \\ Wólczańska 215, 90-924 Lodz, Poland \\ \{olapolak, zwisniewski\}@p.lodz.pl
}

\begin{abstract}
In the 21st century internet is becoming an indispensable element of every person's life. Frequently internet is the basic source of information. Moreover it enables communication, making financial transactions, shopping, etc. Unfortunately in many cases internet applications and sites are not adjusted to psychomotor and perception abilities of the disabled, the number of which is continuously increasing in Poland and all over the world. Very often the sites and applications are illegible and not user-friendly.

The article presents results of the analysis on adjustment of selected Web site and Web browser graphic interfaces to the needs of disabled people.
\end{abstract}

Keywords: web sites, web browsers, internet standards, user interface, disabled people.

\section{Introduction}

In most cases, the problem of Internet accessibility for disabled people is analyzed from two different perspectives: how to eliminate barriers between a disabled person and a computer and how to design and create Web site and Web browser in the appropriate way.

The barrier between a disabled person and a computer can be easily eliminated by means of various tools including speech synthesizers, screen readers, Braille monitors and printers, alternative pointing devices, speech recognition software, etc.

However, such possibilities do not refer to the barrier between a disabled person and a Web site. A Web site can be black-and-white or colourful, with a variety of graphic and multimedia elements, or text-based only. Regardless of its appearance, it can be either accessible to a person with disabilities or very unreadable. There is a variety of obstacles to Web site access including difficulty to read the content by screen readers, problems with navigation (in case of people with motor disabilities), difficulties with associating, understanding and remembering of the content or own location in the Web site, and many others. Given the above, Internet standards play crucial role in an attempt to eliminate such obstacles. The Internet standards are provided in specifications and guidelines of World Wide Web Consortium (W3C), 
organization establishing standards for Web site authors and Web Accessibility Initiative (WAI) - a W3C initiative aimed at providing disabled people with unlimited access to the Internet.

In order to be acquainted with the Web site content, it is not enough to have a properly designed Web site; a web browser is also a must. A web browser is the sole agent between a disabled person and a Web site, or between a Web site and a professional equipment/software enabling or facilitating Web content access.

The WAI initiative includes a working group called User Agent Working Group. UAWG deals with the issue of adjusting the user agents to the needs of people with disabilities. The user agents include Web browsers, media players and assistive technologies [15].

The existing accessibility guidelines User Agent Accessibility Guide (UAAG) pertain to the issue of adjusting Web browsers to the needs of disabled people and focus primarily on Web browser necessary features of to facilitate Internet access. These features include access to all content, user control over how content is rendered, interaction with standard programming interfaces and assistive technologies. With regard to graphic user interface the UAAC only recommends enabling toolbar configuration $[9,15]$. However, it is the design and ergonomics of the user interface that determine its usability for people with disabilities.

The primary aim of this paper is to present results of the analysis on adjustment of selected Web site and Web browser graphic interfaces to the needs of disabled people. This aim was achieved by means of:

- verifying the degree to which Polish Web sites comply with Web content standards; the verification was carried out on the basis of a few simple text;

- verifying the ergonomics level of graphic interfaces of the most common Polish Web browsers.

\section{Internet Standards, WCAG and UAAC}

The issue of Web site availability is first addressed during the stages of designing, planning Web site structure and navigation method and writing HTML/XHTML code. This issue is twofold in nature and can be described by the following questions:

- is Web site code compliant with W3C guidelines and, what follows, is structure separated from presentation?

- is challenging Web site content properly marked and can it be substituted by more accessible one?

Answers to the above questions are provided by $\mathrm{W} 3 \mathrm{C}$ guidelines. The first question is addressed in HTML/XHTML language guidelines; the second issue is discussed in WAI recommendations.

WAI recommendations as of the date of research - Web Content Accessibility Guidelines 1.0 - WCAG 1.0 [18] - are dated 5.05.1999 (the current, updated version is WCAG 2.0. [19]). They are addressed to people who:

- may not be able to see, hear, move, or may not be able to process some types of information easily or at all,

- may have difficulty reading or comprehending text, 
- may not have or be able to use a keyboard or mouse,

- may have a text-only screen, a small screen, or a slow Internet connection,

- may not speak or understand fluently the language in which the document is written,

- may be in a situation where their eyes, ears, or hands are busy or interfered with (e.g. driving to work, working in a loud environment, etc.),

- may have an early version of a browser, a different browser entirely, a voice browser, or a different operating system.

WCAG 1.0 includes fourteen general principles, each principle comprises a list of checkpoints, which must be satisfied in order to enable or facilitate accessibility. WCAG 1.0 recommendations can be fulfilled on one of the three Conformance levels, depending on the type and number of satisfied checkpoints [18].

Priority 1 - A Web content developer must satisfy this checkpoint. Otherwise, one or more groups will find it impossible to access information in the document. Satisfying this checkpoint is a basic requirement for some groups to be able to use Web documents. If all Priority 1 checkpoints are satisfied, the Web site has Conformance level 'A'. A Web site not conforming with Priority 1 requirements must not use any WAI conformance marking.

Priority 2 - A Web content developer should satisfy this checkpoint. Otherwise, one or more groups will find it difficult to access information in the document. Satisfying this checkpoint will remove significant barriers to accessing Web documents. If all Priority 1 and 2 checkpoints are satisfied the Web site has Conformance level 'AA (Double-A)'.

Priority 3 - A Web content developer may address this checkpoint. Otherwise, one or more groups will find it somewhat difficult to access information in the document. Satisfying this checkpoint will improve access to Web documents. If all Priority 1, 2, and 3 checkpoints are satisfied the Web site has Conformance level 'AAA (Triple-A).

Following W3C guidelines with regard to WCAG is the sign of being socially sensitive, professional and precise. An ability to provide services in conformance with any WCAG Priority constitutes competitive advantage of companies dealing with Web site creation.

WAI initiative embraces one more working group called User Agent Working Group, which deals with the aspects of Web browser adjustment to the needs of people with disabilities. Thereby User Agent Accessibility Guidelines (UAAG) have been established [15].

It is a technical document aimed at Web browser designers and developers, nevertheless it has undisputable value to Web site administrators and disabled users. UAAG compliant Web browser enables developers to concentrate on assuring Web site conformity to WCAG instead of software limitations in displaying Web content. Moreover, the users with disabilities can benefit from increased accessibility to Internet resources through a browser or assistive technology.

UAAG provides twelve general guidelines; each principle is further specified by several checkpoints. The guidelines describe functions and technologies a Web browser should be equipped with to enable unlimited Internet access. Checkpoints are grouped in three Priorities indicating how important the checkpoints are for disabled users [15].: 
- If a Web browser does not satisfy Priority 1 checkpoints, people with disabilities will not have access to Web content.

- If a Web browser does not satisfy Priority 2 checkpoints, people with disabilities may have limited access to Web content.

- If a Web browser satisfies Priority 3 checkpoints, people with disabilities will benefit from full access to Web content.

Similarly to Web Content Accessibility Guidelines UAAG uses three Conformance levels 'A', 'Double-A' ('AA') and 'Triple-A' ('AAA') [15].

\section{Legal Requirements Regarding Web Site and Web Browser Adjustment to the Needs of Disabled People}

Although W3C recommendations for Web site and Web browser accessibility do not have legal validity, the activities of World Wide Web Consortium and various organizations dealing with disabilities have led to amendments to the existing law in some countries or adoption of new acts governing Internet accessibility to people with disabilities.

A classic example of such activity is Section 508 [13] - the Act adopted in 1986 by the United States Congress as the amendment to the Rehabilitation Act of 1973, next amended in 1998 to include new technologies. Pursuant to Section 508, each kind of information technology financed by the Federal Government has to provide disabled people with access that is comparable to the access available to others. This Act grants people with abilities the right to take legal action and claim for compensation due to lack of information access. However convergent in a few aspects, the Act is not based on $\mathrm{W} 3 \mathrm{C}$ recommendations.

Legislation of the European Union does not impose obligation to its member countries to adjust Web sites to the needs of people with disabilities. However, it does not mean that this issue is not addressed in European Parliament at all. A number of programs aimed at establishing the needs and legislative perspectives are currently run by the EU [3]. Poland has their representatives in these programs [4]. Due to substantial inertia of European organization, the achievements of individual member countries still remain greater.

The most conspicuous solutions are those implemented by Great Britain. Part III of the Disability Discrimination Act (DDA) [1] - the Act adopted by the Parliament in 1950 corresponds to Section 508. Whereas Section 508 pertains solely to the Web sites financed and maintained by the Federal Government; DDA imposes the obligation to adjust Web sites to the needs of disabled people to companies and nongovernmental organizations, as well. Only individuals are exempt from the Act. Pursuant to the Act, a Web site is obliged to have minimum Priority 1 (Conformance Level A) of WAI recommendations.

Other European countries imposing legal requirements for Web site accessibility adjusted to the needs of people with disabilities include Germany, Ireland, Italy, Portugal, Spain and Switzerland [11].

Compared with the global legislation, Polish achievements in this area are minor. The Act called The Charter of Rights for Disabled People, which refers directly to the 
Constitution of the Polish Republic; does not openly regulate Web site accessibility. Nonetheless some changes have already been introduced. Regulations of the Council of Ministers of 11 October 2005 stipulate the minimum requirements of telematic systems used by public entities to perform public goals and activities. Annex 2, item 5 stipulates which formats are obliged to be used to create and modify Web sites. The formats include HTML 3.2, HTML 4.01, XHTML 1.0, CSS (all formats as per W3C specification). Additionally, pursuant to the statement of the Ministry of Interior and Administration of 12 June 2006 public parties are obliged to provide accessibility until the year 2010, i.e. they should conform to W3C standards and guidelines on Web site accessibility by that time.

\section{The Analysis of Selected Polish Web Sites Accessibility for People with Disabilities (Conformance with Internet Standards and WCAG Recommendations)}

The research on Web site conformity with Internet standards embraced five categories of Polish Web pages:

- Web sites of ministries, as a group legally obliged to conform to particular standards of HTML code,

- Web sites of leading Polish organizations dealing with people with disabilities,

- Web sites of five the most popular portals in Poland,

- Web sites of Internet banks,

- Web sites of state universities.

The appropriateness of HTML and CSS code with current language recommendations has been defined by means of $\mathrm{W} 3 \mathrm{C}$ validation tools [16]. Selection of HTML language was made automatically as per !DOCTYPE markup included in the Web site code and defining HTML version used. If no markup was provided, conformity with the following was verified: HTML 3.2, HTML 4.01 Transitional and XHTML 1.0 Transitional, respectively. Conformity with HTML/XHTML and CSS standards is assessed by marking with '-' (minus) if the Web site failed validation , or giving the name of the used language version in the table if the Website had no inconsistencies. Similarly, CSS code nonconforming to W3C recommendation was marked with '-" (minus), whereas conforming CSS code was marked with '+' (plus).

Conformity with WAI recommendations was verified by means of four common Internet tools - Fujitsu Web Accessibility Inspektor 5.11 [17], Cynthia Says [7], Hera [6] and TAW [14] engines, respectively. The findings of WAI recommendations validation are grouped in the following way:

- bugs: Web site language fragments non-conforming with WCAG guidelines,

- notices: Web site language fragments, which might be non-conforming with WCAG guidelines. Due to subjectivity of some guidelines, the tool is not able to evaluate code fragment appropriateness automatically. In case of notices, it is necessary to evaluate WCAG conformity by a human being.

The research findings are to be read in the following way - symbol ,-" (minus) refers to bugs appearing in Priority 1 checkpoints (Level A). A letter symbol refers to WCAG Conformity Level of code verified automatically (separate validation by the 
human being was not necessary). Although this is not equivalent to full conformity with WCAG recommendations, it quite precisely describes accessibility of the given Web site for disabled people.

Table 1. Governmental Web sites conformity with HTML, CSS standards and WCAG1.0 recommendations (from 09.2008)

\begin{tabular}{|c|c|c|c|}
\hline Web sites & HTML & CSS & WCAG 1.0 \\
\hline Prime Minister & - & + & $\mathrm{A} / \mathrm{A} /-/-$ \\
\hline Ministra of Infrastructure & - & - & $-1-1-1-$ \\
\hline Ministry of Education & - & + & $\mathrm{A} /-1 \mathrm{~A} / \mathrm{A} / \mathrm{A}$ \\
\hline Ministry of Finance & - & - & $-1-1-1-$ \\
\hline Ministry of Economy & - & - & $-/-/-/ \mathrm{A}$ \\
\hline The Ministry of Culture and National Heritage & - & - & $\mathrm{A} / \mathrm{A} /-/ \mathrm{A}$ \\
\hline Ministry of Science and Higher Education & - & - & $-1-/-/-$ \\
\hline $\begin{array}{l}\text { Ministry of Science and Higher Education } \\
\text { (version for sand-blind) }\end{array}$ & - & - & $\mathrm{A} / \mathrm{A} / \mathrm{A} / \mathrm{A}$ \\
\hline Ministra of National Demence Republic of Poland & - & - & $-1-/-1-$ \\
\hline Ministra of Labour and Social Policy & - & - & $-1-/-1-$ \\
\hline $\begin{array}{l}\text { Ministra of Labour and Social Policy } \\
\text { (version for sand-blind) }\end{array}$ & - & - & $-1-1-1-$ \\
\hline Ministry of Agriculture and Rural Development & - & - & $-1-1-1-$ \\
\hline Ministry of Regional Development & - & - & $-1-1-1-$ \\
\hline Ministry of Treasury & $\begin{array}{l}+ \text { xhtml } 1.0 \\
\text { Transitional }\end{array}$ & - & $\mathrm{A} / \mathrm{A} / \mathrm{A} / \mathrm{A}$ \\
\hline Ministry of Sport and Tourism & - & - & $\mathrm{A} / \mathrm{A} /-/-$ \\
\hline Ministry of Justice & - & - & $\mathrm{A} /-/ \mathrm{A} / \mathrm{A}$ \\
\hline Ministry of Interior and Administration & - & - & $-1-1-1-$ \\
\hline Ministry of Foreign Affairs of the Republic of Poland & - & - & $-/-/-/-$ \\
\hline Ministry of Health & - & - & $-1-1-1-$ \\
\hline
\end{tabular}

Table 2. Leading Polish portals conformity with HTML, CSS standards and WCAG1.0 recommendations (from 09.2008)

\begin{tabular}{lccc}
\hline Web sites & HTML & CSS & WCAG 1.0 \\
\hline www.onet.pl & - & - & A / / A / A \\
www.gazeta.pl & - & - & $-/$ / / / - \\
www.wp.pl & + xhtml 1.0 Strict & - & $-/$ / / - \\
www.interia.pl & - & - & A / A / A / A \\
www.o2.pl & - & - & $-/$ / / / - \\
\hline
\end{tabular}


Table 3. Web sites for and about people with disabilities conformity with HTML, CSS standards and WCAG1.0 recommendations (from 09.2008)

\begin{tabular}{lccc}
\hline Web sites & HTML & CSS & WCAG 1.0 \\
\hline www.idn.org.pl & + HTML 4.01 Strict & + & A / A / A / A \\
www.ffm.pl & - & - & - / - / / - \\
www.pfron.org.pl/portal/pl/ & + xhtml 1.0 Transitional & - & - / - / - / - \\
www.pfron.org.pl/wai/pl/ & + xhtml 1.0 Transitional & + & A / A / A /A \\
(version for sand-blind) & - & - & - / - / / A \\
www.ngo.pl & - & - & - / - / - / - \\
www.ipon.pl & - & + & - / - / - / - \\
www.pelnosprawniwpracy.pl & - & + & A / A / A / A \\
www.niepelnosprawni.pl & - & &
\end{tabular}

Table 4. Selected e-bank websites conformity with HTML, CSS standards and WCAG1.0 recommendations (from 09.2008)

\begin{tabular}{lccc}
\hline Web sites & HTML & CSS & WCAG 1.0 \\
\hline www.pekao.com.pl/ & - & + & $-/-/-/-$ \\
www.pkobp.pl/ & - & - & $-/-/-/-$ \\
www.mbank.pl/ & - & - & $-/-/-/-$ \\
www.lukasbank.pl/ & - & - & $-/-/-/-$ \\
www.deutsche-bank-pbc.pl/ & - & - & $-/-/-/-$ \\
www.multibank.com.pl/ & - & - & $-/-/-/-$ \\
www.citibank.pl/poland/homepage/ & - & - & A / A/ A /A \\
\hline
\end{tabular}

Table 5. Conformity of selected state university websites with HTML, CSS standards and WCAG1.0 recommendations (from 09.2008)

\begin{tabular}{|c|c|c|c|}
\hline Web sites & HTML & CSS & WCAG 1.0 \\
\hline www.uni.lodz.pl/ & - & - & $-1-/-1-$ \\
\hline www.uw.edu.pl/ & - & - & $-1-1-1-$ \\
\hline www.uj.edu.pl/index.html & - & + & $-1-1-1-$ \\
\hline www.p.lodz.pl/index.htm & - & - & $-1-/-1-$ \\
\hline www.pw.edu.pl/ & + XHTML 1.0 Transitional & - & $\mathrm{A} / \mathrm{A} / \mathrm{A} / \mathrm{A}$ \\
\hline www.put.poznan.pl/ & - & - & $-/-1-/-$ \\
\hline www.pwr.wroc.pl/ & - & - & $-1-1-1-$ \\
\hline www.pk.edu.pl/ & - & + & $-1-1-1-$ \\
\hline
\end{tabular}


The results of performed test are straightforward - Polish Web sites in most cases do not conform to $\mathrm{W} 3 \mathrm{C}$ recommendations. Some nonconformities like lack of HTML and CSS code validation in case of private or commercial parties can be overlooked. However, for public entities they constitute not only bad practice by also violation of the law.Web site accessibility for disable people is also far from perfection - among 19 governmental Web pages 11-failed automatic validation against WAI recommendations at the lowest level. Among sites for and about disabled people only three managed to reach Level 'A' and one only in one (out of four) tests. In case of ebanks and state universities, the results were worse (only two managed to reach Level 'A' ). In this group, the most spectacular results were obtained by two sites for and about disabled people (www.idn.org.pl; http://www.pfron.org.pl/wai/pl/ - version for sandblind), which passed both HTML code validation and automatic verification against conformance with WCAG for Priority 1 (Level A) by all four tools.

\section{The Analysis and Evaluation of Web Browser Graphic User Interface Adjustment to the Needs of People with Disabilities}

Currently more than fifty graphic Web browsers for various operating systems using graphic user interface are available on the market. However, in reality over $99 \%$ of page hit including global and Polish Internet are generated by means of the following Web browsers: Internet Explorer (version 6 and 7), Firefox, Opera, Safari and [12].

Hassle-free use of Web browser interface by the disabled is hindered by the fact that most browser solutions are too universal to satisfy the needs of different groups of users. Due to some limitations in this paper, the author decided to focus on the analysis and assessment of selected Web browser graphic interface features.

In case of people with disabilities, various elements can pose difficulties, which are related with the type of user disability.

For people with restricted motor abilities the most crucial aspect is easy and simple access to browser controllers. They should be large and placed close to the pointer.

All common Web browsers have almost identical navigation menu, they can be distinguished by some details only - navigation button, address bar, search box and other controllers are located in toolbar in the upper part of the screen. If a person with restricted motor abilities wants to use any of these elements, they have to locate pointer above it, making a movement with a pointing device. It substantially prolongs the time of the operation.

Access to a context menu (which appears upon right mouse click) would be a much more convenient solution. The context menu includes the core options in any part of the screen. The most options are provided by Opera and IE6, the next are Safari and Firefox.

Yet another Web browser facility for people with restricted motor ability is additional program (plugin) providing context menu or enabling use certain pointer moves as commands. Such programs include Mouse Gestures [1] or easyGestures [2], which are Firefox plugins. Opera provides a facility similar to Mouse Gestures.

For deaf and hard of hearing people, a Web browser should provide visual equivalent to all sound alerts. In particular, it refers to alerts likely to appear, when the sight is not directed to the screen (e.g. while typing). Among four the most common browsers only Opera provides sound alert function but without visual equivalents. [9] 
People with sensor and intellectual disabilities may have problems with reading, understanding and recognizing the content, hence they should need some navigation guidelines in the form of symbols and icons pertaining to everyday experience and additionally labeled with text description. Controllers should be large and limited in number, graphic design simple with a minimum number of graphics and colours. Sophisticated colouring might hinder accessibility to people with defective perception of colours. Good examples of clear and simple graphic structure are Firefox and Safari. The opposite is Opera, whose interface is information overloaded, which can impede orientation and concentration.

Moreover, the structure of preference (settings) panel should be as simple and easy to navigate as possible, which is to the benefit of all people with disabilities. Moreover, preference panel should contain icons and symbols, if possible. Firefox and IE7 provide a readable preference panels.

Web browser signaling elements should be visible and not causing disorientation by displaying inadequate messages. These elements include progress bar, antyphishing filter feedback. Due to security reasons, issues of proper signaling of secure connection initiating and terminating are essential. Safari definitely falls behind in this category; such information is displayed as a small icon in the upper right corner of the title bar. IE6 solution is similar; a slightly larger icon is placed at the bottom of the screen. Other browsers change colour of the address bar or its part to make this information more legible.

According to UAAG recommendations, a Web browser should enable modification of toolbar and adjustment to the needs of people with disabilities. Here the most advanced are Opera programmers who managed to offer user interface adjustment on a grand scale - not only the type and number of displayed icons can be set, but also location of toolbars. Firefox, Safari and Internet Explorer only enable basic adjustments of the toolbar.

\section{Conclusion}

Despite the fact that by 2010 all Polish public We site should have conformed to W3C standards and guidance on Web site accessibility, the obtained results are not promising - Polish Web sites do not tend to follow W3C recommendations. Web site accessibility for people with disabilities has many shortcomings as well. Nonconformance with WCAG recommendations at the lowest level in most cases is probably connected with simple errors not directly affecting Web page accessibility (e.g. lack of text equivalents for graphic content). On the other hand, in majority of case it is possible to conclude that Webmasters and Web moderators are not acquainted with the issue of Web site accessibility for disabled people. This situation is the most disappointing in case of Web pages aimed at people with disabilities, which should particularly focus on theses aspects.

The analysis of the most common Web browser graphic user interface adjustment to the needs of people with disabilities resulted in a number of discrepancies, too.

Modern Web browser graphic user interface id directly determined both by the shape of first Web browser software interface and by GUI concept developed by Xerox in the early 1970s. The first commercial realization of the GUI concept was available in Apple computers in the first half of 1980s. Thus, Web browser interfaces 
base on solutions, which are more than thirty years old. Given that all current graphic operating systems use the same approach to graphic interface, which is called WIMP (Windows, Icons, Menus, Pointing device), the fact that all Web browser resemble one another is not surprising at all.[9]

The shape of software interface is a mixture of user habits, ergonomic values, marketing decisions and target users. As for the last factor, in a majority of cases the main users are represented by people with full abilities. Thereby the graphic user interface design focuses on attractiveness rather than functionality for the disabled.

It is worth mentioning that Web browser are more and more frequently used in mobile phones, PDA devices, TV sets, game consoles, Internet kiosks rather than computers. This migration results in a number of browser interface changes pertaining to the ability to display Web content on a screen with much lower resolution than computer monitor has. In addition, the method of interaction with browser differs instead of full-size keyboard and a pointing device, a touch screen or small phone keyboard is used. Latest technology solutions are gaining new markets rapidly; however, the problem of Internet accessibility for disabled people of these solutions has not been addressed. Thus, new technologies might contribute to social divide of the disabled due to low accessibility and ergonomics inadequate for people with disabilities.

\section{References}

1. Disability Discrimination Act 1995, http://www.opsi.gov.uk/acts/acts1995/1995050.htm

2. EasyGestures, http: // easygestures.mozdev.org/

3. Europe's Information Society, http://ec.europa.eu/information_society/policy/

4. European Internet Accessibility Observatory, http: / / www . eiao. net/

5. Fitts, P.: The information capacity of the human motor system in controlling the amplitude of movement. Journal of Experimental Psychology 47(6) (1954)

6. HERA: Cascading Style Sheets for Accessibility Review, http: / / www. sidar.org/hera/, http: / /www. sidar.org/hera/

7. HiSoftware ${ }^{\circledR}$ Cynthia Says ${ }^{\mathrm{TM}}$ Portal, http: / / www. contentquality.com/

8. Krzciuk, B.: Web sites user-friendly for people with disabilities - web standards, Warsaw (2006)

9. Krzciuk, B., Miarka: Ergonomics of web browser graphic user interface, Warsaw (2007)

10. Mouse Gestures, http: / / optimoz . mozdev. org/gestures /

11. Policies Relating to Web Accessibility, http: / /www . w3 . org/WAI / Policy /

12. Ranking, http://www.ranking.pl/

13. Section 508, http://www. section508.gov/

14. TAW, http: //www. tawdis.net/

15. User Agent Accessibility Guidelines, http://www.w3 . org/TR/UAAG10/

16. W3C Quality Assurance Tools, http: / / www.w3 .org/QA/Tools /

17. Web Accessibility Inspector, http: //www. fujitsu.com/global/

18. Web Content Accessibility Guidelines 1.0, http: / /WWw.w3 . org/TR/WCAG10/

19. Web Content Accessibility Guidelines (WCAG) 2.0, http: / / www.w3 .org/TR/2008/REC-WCAG20-20081211/ 